Marquette University

e-Publications@Marquette

College of Education Faculty Research and

Publications

Education, College of

$10-1-2006$

\title{
Researchers at the Gate: Factors Influencing Districts' Right of Entry Decisions
}

Steven A. Melnick

Bill Henk

Marquette University, william.henk@marquette.edu

Accepted version. Educational Administration Quarterly, Vol. 42, No. 4 (October 2006): 652-661. DOI. (C) 2006 SAGE Publications. Used with permission. 


\title{
Researchers at the Gate: Factors Influencing Districts' Right of Entry Decisions
}

\author{
Steven A. Melnick \\ Teaching and Curriculum, Penn State Harrisburg \\ Harrisburg, $P A$ \\ William A. Henk \\ School of Education, Marquette University \\ Milwaukee, Wisconsin
}

\begin{abstract}
:
Background: The No Child Left Behind legislation creates an increased need for new school-based empirical studies whose implementation will depend largely on researchers' access to various school populations and records. Access decisions are typically made by superintendents, or their designees, functioning as gatekeepers who control right of entry. Understanding the factors driving these decisions could enhance the desirability of proposals and increase access rates for quantitative and qualitative researchers alike.

Purpose: The purpose of this research was to query districts about four key access factors including (a) researcher trustworthiness, (b) associated risks, (c) costs and benefits, and (d) potential contribution to the field.

Research Method: This study used a series of interviews followed by a systematic survey.

Participants: Ten superintendents were interviewed followed by a survey of 310 districts in Connecticut, Illinois, and Pennsylvania.

Educational Administration Quarterly, Vol. 42, No. 4 (October 2006): pg. 652-661. DOI. This article is (C) SAGE Publications and permission has been granted for this version to appear in e-Publications@Marquette. SAGE Publications does not grant permission for this article to be further copied/distributed or hosted elsewhere without the express permission from SAGE Publications.
\end{abstract}


Findings: Although trustworthiness was expected to supercede other factors, districts reported greater interest in elements of risk and in research having widespread educational value. Costs and material benefits (e.g., equipment, credit, and compensation) were not highly emphasized nor relatively important. Professional development, planning, and instructional benefits mattered more.

Implications for Research and Practice: Given the increasing emphasis on scientifically based research for school decision-making and program reform, the present study is notable for two reasons. First, it provides researchers with insights into the decision-making process involved in granting permission to conduct research in the schools. Second, it can help to improve the quality of proposals received by school districts, thereby increasing the likelihood of positive right-of-entry decisions and resulting in better informed decisions.

The No Child Left Behind (NCLB) Act has focused national attention on the need for more school-based research particularly in terms of instructional strategies, parental involvement, and schoolwide reforms (NCLB, 2001). This legislation requires schoolwide improvement through the use of empirically validated instruction, a demonstrated consideration of current research on effective parental involvement (NCLB, 2001, Part A, Subpart 1: Sec. 1111.d.1), and otherwise taking into account "the findings of relevant scientifically based research" (NCLB, 2001, Part A, Subpart 1: Sec 1112.C.1.f).

In fact, the NCLB Act has significantly amplified the interest in all types of school-based inquiry. Despite this heightened interest, researchers external to schools (e.g., those in university settings, regional laboratories, human service agencies, etc.) often report frustration in gaining access to student, teacher, and administrative populations for the purposes of collecting data that meets the NCLB expectations. Given that school personnel must contend with myriad responsibilities, new initiatives, and public criticisms, researchers frequently find that participating in a research study does not rank as a very high priority among districts, particularly if there are perceived risks. Although some literature exists regarding school leadership and risk taking, none focuses on the potential risks involved in permitting outside researchers access to students and staff.

Brunner (1999) points out that risk taking in general is critical to successful leadership but found very few references to risk taking specifically. She points out the dissonance between the literature on characteristics of successful leadership, which typically include risk taking, with conflicting literature indicating that superintendents are not themselves risk takers (Konnert \& Gardner, 1987; Short \& Greer,

Educational Administration Quarterly, Vol. 42, No. 4 (October 2006): pg. 652-661. DOI. This article is (C) SAGE Publications and permission has been granted for this version to appear in e-Publications@Marquette. SAGE Publications does not grant permission for this article to be further copied/distributed or hosted elsewhere without the express permission from SAGE Publications. 
2001). Numerous studies examine the characteristics and competencies of successful superintendents, but none identify risk taking as one of them (e.g., Carter, Glass, \& Hord, 1993; Haugland, 1987).

Davis (2005) identifies 15 common traps befalling school administrators in making decisions. Among them is a tendency for administrators to react to relatively small groups of disgruntled constituents in the hope of avoiding emotionally charged issues. Additionally, school leaders may be more inclined to give more weight to information that confirms what we already know (Davis, 2005). Consequently, when faced with a proposal to conduct research involving students and staff, school leaders will likely avoid potentially controversial or risky research projects.

In fact, when permission to conduct research is granted, it is often the case that the researchers gain access on the basis of having made some personal connection to the school, either by virtue of a relationship with a current or former graduate student who is a member of the staff or through their own outreach, consulting work, or reputation. In other instances, access to school-based populations is sometimes a function of chance. For example, Todman, Crombie, and Keighren (1990) report that they received access to a school population based on a fortuitous encounter in a school whose teachers had just been discussing the research issue in the faculty lounge. The teachers' receptiveness to the research was piqued after having seen a television show that aired a segment on a similar issue. At the same time, however, researchers seeking right of entry might benefit from understanding the culture of schools and the issues that might intrigue their personnel rather than relying on factors of chance or personal connections. By our way of thinking, it figures that school officials would be inclined to grant access to trustworthy researchers who propose beneficial projects that are virtually risk-free, carry little or no cost, and offer the distinct promise of contributing to the field of education broadly. In contrast, when researchers are not well known to school officials and their proposals represent potentially risky, resource-intensive ones with limited generalizability, the chances of collecting data in school contexts would stand to diminish dramatically. To date, although this thinking represents speculation at best, the extent to which these factors influence right of entry decisions, both alone or in combination, is not known. 
NOT THE PUBLISHED VERSION; this is the author's final, peer-reviewed manuscript. The published version may be accessed by following the link in the citation at the bottom of the page.

\section{Theoretical Perspectives}

In point of fact, few studies have been conducted to determine how district administrators view educational research in the schools generally, let alone how they approach gatekeeping decisions. In one general study, West and Rhoton (1994) conducted a statewide survey of school administrators in Tennessee to ascertain their overall attitudes toward educational research. It was found that administrators believe research is often difficult to understand, too technical, and impractical. One lesson here would seem to be that it behooves researchers to demystify their oral and written proposals for access, clearly explaining the nature of the proposed work and its applied benefits.

Beyond these findings, however, our search of the educational literature revealed no existing theoretical framework for interpreting the gatekeeping process. For this reason, it was necessary to collect preliminary qualitative data on the chance that we might find some direction for exploring other literatures that might illuminate right of entry decisions. Our initial thought was to go close to the source, so we invited a small group of former superintendents who worked at our institution to a focus group session. In that session, we directly asked what factors were important to them in making the decision to allow researchers access to their schools when they were in office. Five possible factors emerged from that informal discussion including (a) trust-whether the researcher is regarded as being serious, ethical, considerate, and trustworthy; (b) risk assessment-a determination as to whether there is any discernible downside to the district in permitting the proposed research; (c) benefit-the extent to which the proposed research might be advantageous for either the district or its gatekeeper; (d) cost assessment-whether the district's involvement would require supplying any human or financial resources; and (e) contribution-the value of any potential contribution the proposed research might add to the field of education. A determination of which factors districts weigh most heavily in their decisions about right of entry could conceivably help researchers to better understand the gatekeeping process, enhance the strategic impact of their proposals, and lead to greater access to the school-based populations necessary to meet the standards of scientifically based and qualitative forms of inquiry. 
NOT THE PUBLISHED VERSION; this is the author's final, peer-reviewed manuscript. The published version may be accessed by following the link in the citation at the bottom of the page.

\section{Method}

To build on the focus group data, we decided to secure final direction by going right to the source. In a qualitative interview study (Melnick \& Henk, 2002), we questioned a total of 10 local, current school superintendents individually in 1-hr sessions to determine what factors they reported in making access decisions. Although a structured interview protocol guided the sessions, the superintendents were given the opportunity to discuss any factors they thought to be worth mentioning.

Beyond proximity, these 10 superintendents were selected for two reasons. First, their districts receive numerous requests for research studies each year. Thus, this type of decision making would be practiced by them regularly. Second, the level of comfort and trust we shared with these particular superintendents ensured that we would receive very candid and thorough responses to our questions. In short, this group could be counted on to forgo politically correct, socially desirable, or superficial responses that might misdirect us. On the contrary, we received honest and deeply thoughtful feedback that would clearly inform the development of a broad-based, strategic survey instrument.

It so happened that our original brainstorming session with the former superintendents effectively foreshadowed our formal interviews with the standing superintendents. Use of the structured interview protocol revealed that the same five basic factors were of equal concern to the standing superintendents as well (i.e., trustworthiness, risk, costs, benefits, and contribution to the field). However, because cost and benefit assessments were closely interdependent concepts in these superintendents' remarks, it was decided to combine them into one more inclusive category (i.e., cost/benefit). This adjustment resulted in four primary theoretical factors that could be investigated more extensively with a systematic survey instrument.

Based on these final interview results, a survey tool was devised to explore the four-factor gatekeeping model. More specifically, the purpose of the survey was to obtain input from a much more expansive cross section of superintendents to help us understand the relative importance of the factors as well as their respective interplays. Using instrument development techniques for affective measures (Gable \& Wolf, 1993), we created a 40-item survey that was systematically organized into 10 clusters of 4 items each. All of the 
clusters contained 1 item representing each of the 4 factors (i.e., trust, contribution, risk, cost/benefit). The survey asked respondents to evaluate the items in two different ways. First, they were asked to rate the extent to which they emphasized each factor separately when making a decision about whether to allow a researcher into their districts (i.e., not at all, a little, some, much, a great deal). This rating was considered the emphasis score. Second, within each set of four statements, respondents were asked to rank order each statement from 1 to 4 ranging from the one that they considered to be the most important to the item they considered to be least important. This forced-choice ranking was regarded as the relative importance score.

\section{Data Source}

A total of 1,000 surveys were sent to randomly selected superintendents in three states. Surveys were returned by 310 respondents, yielding a $31 \%$ response rate representing rural, suburban, and urban districts. Of the respondents, 93\% were superintendents, $4 \%$ were assistant superintendents, and the remaining $3 \%$ were a variety of superintendents' designees. Respectively, the respondents were from Connecticut $(n=40)$, Illinois ( $n=166)$, and Pennsylvania $(n=104)$.

\section{Results}

Our first interest was in knowing the extent to which districts had formal procedures or policies in place for determining right of entry. The demographic portion of the survey asked respondents to indicate if their districts had any existing internal guidelines or formal application processes for conducting research. Interestingly, only $28 \%$ of the districts reported having procedures on hand for conducting research in their schools, and just $11 \%$ had any type of formal application process. These data suggest that access to school populations is apparently governed by informal procedures primarily; however, similar to all of the survey findings, this result could be an artifact related to the particular administrators who chose to complete the instrument.

Another demographic we sought was the estimated number of requests for research access that the respondents received per year. Thirteen percent of the respondents indicated they receive virtually no requests for research access. The remaining $87 \%$ of the respondents 
indicated receiving a range of relatively few to as many as 150 per year. Approximately $35 \%$ indicated they receive 10 or more requests per year.

The findings of primary interest center on the emphasis and relative importance data. Descriptive statistics from the 310 surveys are presented in Tables 1 through 3 . The data represent the scale means, sample, and frequency of responses to individual items. Recall that for each item, respondents were asked to rate the emphasis they gave each item in making gatekeeper decisions (i.e., not at all to a great deal) and to rank order the items by relative importance, forcing choices among the four factors represented in each set (i.e., trust, risk, cost/benefit, and contribution). Table 1 indicates the means and standard deviations for each of the four scales (i.e., contribution, cost/benefit, risk, trust). Table 2 displays the top three and lowest three items based on rank ordering of emphasis means, whereas Table 3 shows the top and lowest three relative importance ranks.

Risk to the district and superintendent emerged as the single most important factor (i.e., scale) by decision makers when considering researchers' right of entry to their schools (scale mean $=$ 4.19; see Table 1). Additionally, based on both the means and rank ordering of individual items, risk items were considered among the highest in both emphasis and relative importance (see Tables 2 and $3)$. In fact, risk clustered within the top eight ranked relative importance items overall.

Contribution to the field was given considerably more relative importance by the respondents than expected. In fact, the scale mean for contribution achieved the second highest rating (mean $=3.86$ ) of the four factors (see Table 1). At the same time, only one contribution item fell among the top 10 ranked items in overall emphasis (i.e., "The decision makers genuinely recognized the value of the research to the field"). Interestingly, respondents rated that item in emphasis as ranging from much to a great deal when placing it individually on a 5point scale $(M=4.26)$, making it the fifth highest rated item. However, when forced to rank order the item by considering its relative importance, the item dropped to 10 th overall. The final noteworthy aspect of the contribution scale findings derived from the fact that three of its items were ranked lowest in terms of emphasis (see Table 2). 
The cost/benefit factor generated the third highest scale mean at 3.68. The respondents rated the item "The district might benefit from some new instructional techniques used in the research project" as the second overall most important aspect (see Table 3). Additional items related to professional benefits, such as the "Information from the project might be useful in school planning" and "Participants might benefit from the experience" were also rated highly in relative importance and were among the top 10. Cost/benefit items that focused on issues not directly related to instruction and planning (e.g., the receipt of equipment, formal credit, and compensation) ranked among the lowest overall.

Items related to trustworthiness were clearly regarded lower than anticipated. Based on the literature review, our superintendent interviews, and our own experience, it was expected that trust would be the predominant factor emphasized by respondents. We also assumed that it would rank high in relative importance. Surprisingly, the trust factor represented the lowest rated relative importance scale with a mean of 3.62, and 5 of the trust items were among the lowest 10 items in emphasis; 4 of the trust items were among the lowest 10 items in relative importance.

\section{Discussion}

Although trustworthiness was expected to be the most highly emphasized and ranked scale, districts were far more concerned about elements of risk and placed a high value on the contribution that a proposed study might make to the field. Trust actually evidenced the lowest overall rating and ranking. Benefits related to professional issues such as instruction and planning were more important to districts than material rewards for the district or external rewards for the participants. Costs did not seem to figure very prominently in their thinking.

Although the four factors explored in this study varied in reported emphasis and relative importance, our overarching sense is that researchers need to be sensitive to all of them. Although the emphasis means for contribution to the field, costs/benefits, and researcher trustworthiness all fell into the range between much and $a$ great deal; only the risk factor seemed to diverge prominently from the others. This virtual equality suggests that there is probably an 
unavoidable capacity for interaction among all of the factors that will make nearly all gatekeeping decisions unique to some extent.

Still, it is understandable why elements of risk represent such an important consideration for districts. Administrators are professionally and ethically obligated to operate in the best interest of their districts, and they shoulder the ultimate responsibility for safeguarding the welfare and rights of all students, faculty, and staff. Interestingly, official clearance by the university's institutional review boards was not routinely accepted as compelling by the superintendents. We got the distinct sense that they preferred to scrutinize proposals themselves and make their own risk assessments. This preference is not surprising because they would be the ones held accountable if anything should go awry.

\section{Final Thoughts}

Future researchers might consider three aspects of this study. First, the present study included districts in 3 states. A representative number of districts from all 50 states would provide a more accurate snapshot of districts nationwide. Second, the results of this survey are based on self-report data. Third, in the present study, cost/benefit was considered one factor. Greater delineation between these two factors might provide additional information regarding what districts tend to value. In fact, greater scrutiny of the relationships between high or low cost versus high or low benefit would isolate the individual factors further and enhance our understanding of the interrelationships among them. Additionally, researchers and administrators should consider the following. With $87 \%$ of the districts getting some requests, and $35 \%$ getting 10 or more requests per year, districts would be well advised to develop policies for research in the schools. Only $28 \%$ had written procedures, but only $11 \%$ had a formal application process.

Furthermore, as risk was the area of most concern to districts, researchers should clearly and completely identify the potential risks and provide detailed explanations as to how those potential risks will be minimized or eliminated. Last, researchers need to be clear as to what benefits the district might realize from their participation. In particular, benefits related to possible new or improved instructional techniques or other professional benefits should be highlighted. Far less interest is shown in anything not related to potential gains in achievement (e.g., compensation, equipment, credit, etc.). And finally, 
it also appears desirable to highlight the potential contribution of the proposed research to the field of education and to detail the professional benefits to the school district.

In sum, when seeking right of entry, investigators should never lose sight of the fact that research is not the primary business of schools. Although the need for scientific evidence is certainly not lost on school administrators, they view its discovery as the responsibility of individuals from outside their immediate contexts. At best, external investigators are guests in the schools. They are permitted to do their work by virtue of a courtesy that has been extended to them. It is important, then, that researchers remain respectful of school cultures and ever mindful of the privilege their access represents. Clearly, those seeking access to schools need to recognize that the gatekeeping function of superintendents and other school officials carries enormous responsibility. By tending to these considerations and bringing the findings of the current study to bear, researchers should have a better chance of getting their foot in the gate.

\section{Notes}

- The authors wish to thank Elizabeth Andrews for her assistance in the preparation of the background research for this article.

- Steven A. Melnick is an associate professor of education and coordinator of the graduate program in Teaching and Curriculum.

- William A. Henk is the dean of the School of Education at Marquette University in Milwaukee, Wisconsin.

\section{References}

Brunner, C. C. (1999). Taking risks: A requirement of the new superintendency. Journal of School Leadership, 9, 290-310.

Carter, D. S., Glass, T. E., \& Hord, S. M. (1993). Selecting, preparing and developing the school district superintendent. Washington, DC: Falmer.

Davis, S. H. (2005). What was I thinking? Common traps in administrative decision making of superintendents and principals. The School Administrator, 6(82), 36.

Gable, R. K., \& Wolf, M. B. (1993). Instrument development in the affective domain: Measuring attitudes and values in corporate and school settings. Boston: Kluwer.

Haughland, M. (1987). Professional competencies needed by school superintendents as perceived by school board members and superintendents in South Dakota. ERS Spectrum, 5, 409-442.

Educational Administration Quarterly, Vol. 42, No. 4 (October 2006): pg. 652-661. DOI. This article is (C) SAGE Publications and permission has been granted for this version to appear in e-Publications@Marquette. SAGE Publications does not grant permission for this article to be further copied/distributed or hosted elsewhere without the express permission from SAGE Publications. 
NOT THE PUBLISHED VERSION; this is the author's final, peer-reviewed manuscript. The published version may be accessed by following the link in the citation at the bottom of the page.

Konnert, M. W., \& Garner, J. B. (1987, Spring). Assessing and altering risktaking propensity: Keys to superintendent success. Catalyst, pp. 7-12.

Melnick, S. A., \& Henk, W. A. (2002, October). Superintendents' views on conducting research in the schools. Paper presented at the annual conference of the Northeastern Educational Research Association, Kerhonkson, NY.

No Child Left Behind Act, Pub. L. No. 107-110 (2001).

Short, P., \& Greer, J. T. (2001). Leadership in empowered schools: Themes from innovative efforts (2nd ed.). Upper Saddle River, NJ: Merrill.

Todman, J., Crombie, I., \& Keighren, J. (1990). Protracted intrusive research in the schools: Why us? Educational Studies, 16(2), 141-149.

West, R. F., \& Rhoton, C. (1994). School district administrators' perceptions of educational research and barriers to research utilization. ERS Spectrum, 12, 23-30.

\section{Appendix}

Table 1. Rank-Ordered Scale Means and Standard Deviations

\begin{tabular}{|l|c|c|}
\hline \multicolumn{1}{|c|}{ Scale } & M & SD \\
\hline Risk & 4.19 & .49 \\
\hline Contribution & 3.86 & .58 \\
\hline Cost/benefit & 3.68 & .59 \\
\hline Trust & 3.62 & .57 \\
\hline
\end{tabular}

Table 2. Top- and Bottom-Ranked Items by Emphasis

\begin{tabular}{|l|c|}
\hline \multicolumn{1}{|c|}{ Item } & M \\
\hline Top Three Ranked Items & 4.44 \\
\hline $\begin{array}{l}\text { E23. Assurances were given that data would be confidential and the school entities } \\
\text { and participants would remain anonymous (Privacy Act). (Risk) }\end{array}$ & 4.48 \\
\hline E25. The project would cause little or no disruption in normal operations. (Risk) & 4.39 \\
\hline E3. The project complied with school policies. (Risk) & 3.06 \\
\hline Lowest Three Ranked ltems & 2.96 \\
\hline $\begin{array}{l}\text { E6. The schools would receive equipment or resources as a result of participating in } \\
\text { the project. (Cost/benefit) }\end{array}$ & 2.36 \\
\hline E18. Participants would receive formal credit for their efforts. (Cost/benefit) \\
\hline E2. Participants would be compensated for their time. (Cost/benefit) &
\end{tabular}

Educational Administration Quarterly, Vol. 42, No. 4 (October 2006): pg. 652-661. DOI. This article is (C) SAGE Publications and permission has been granted for this version to appear in e-Publications@Marquette. SAGE Publications does not grant permission for this article to be further copied/distributed or hosted elsewhere without the express permission from SAGE Publications. 
NOT THE PUBLISHED VERSION; this is the author's final, peer-reviewed manuscript. The published version may be accessed by following the link in the citation at the bottom of the page.

Table 3. Top- and Bottom-Ranked Items by Relative Importance

\begin{tabular}{|c|l|}
\hline Rank Order & \multicolumn{1}{c|}{ Item } \\
\hline 1 & 135. The project would cause little or no disruption in normal operations. (Risk) \\
\hline 2 & $\begin{array}{l}\text { 138. The district might benefit from some new instructional techniques used in } \\
\text { the project. (Cost/benefit) }\end{array}$ \\
\hline 3 & $\begin{array}{l}\text { 17. The data would be put to ends that were deemed desirable by the school } \\
\text { district and professional participants. (Risk) }\end{array}$ \\
\hline 38 & 129. Oral descriptions of the proposed project were of high quality. (Trust) \\
\hline 39 & 133. The researchers were willing to compromise. (Trust) \\
\hline 40 & 12. Participants would be compensated for their time. (Cost/benefit) \\
\hline
\end{tabular}

Educational Administration Quarterly, Vol. 42, No. 4 (October 2006): pg. 652-661. DOI. This article is (C) SAGE Publications and permission has been granted for this version to appear in e-Publications@Marquette. SAGE Publications does not grant permission for this article to be further copied/distributed or hosted elsewhere without the express permission from SAGE Publications. 